\title{
Erratum: In situ nanoindentation study on plasticity and work hardening in aluminium with incoherent twin boundaries
}

\author{
D. Bufford, Y. Liu, J. Wang, H. Wang \& X. Zhang
}

Nature Communications 5:4864 doi: 10.1038/ncomms5864 (2014); Published 10 Sep 2014; Updated 17 Nov 2014

There were errors associated with the order of the Supplementary Movies in the version of this Article originally published, which were introduced while the HTML was being prepared. The files of Supplementary Movies 1, 2, 3, 4, 5 and 6 were incorrectly exchanged with those of Supplementary Movies 6, 5, 4, 3, 1 and 2, respectively. These errors have now been corrected in the HTML version of the Article; the PDF was correct from the time of publication. 